mentally will be dealt with also in terms of theory. It has already been found that more projects are coming along for calculation than can be dealt with by the number of staff originally planned. Among such problems are the heat transfer in continuous casting, the effect of oxygen on the thermodynamics of the blast furnace, the statics of furnace roofs when made with basic bricks, heat transfer in immersion pyrometers and in furnace systems, and the thermodynamics of the Bessemer converter.

There is also provision at the Physies Department's laboratories for a laboratory for the Association's Chemistry Department, and one for the Steelmaking Division. The former is devoted to investigations into the fundamental thermodynamic and kinetic aspects of the behaviour of iron and other elements during the process of iron and steel making. Dr. F. D. Richardson is in charge of this Department. The Steelmaking Division (under Dr. A. H. Leckie) carries out at Battersea work connected with instruments and process chemistry. In this connexion guests at the opening were able to inspect a mobile laboratory for use in steel works, which, mounted on an ex-army lorry chassis, has been designed by the Steel-making Division and assembled at the Physics Laboratories.

\section{MARKET RESEARCH}

$\mathrm{T}$ HE importance to the manufacturer of acquiring accurate knowledge of his market is now becoming generally recognized. Should there have been any residual doubts, they were rapidly dispelled at the conference on market research conducted by the Manchester Joint Research Council on October 22, when the following papers were presented: "The Technique and Applications of Market Research", by Mr. O. W. Roskill (sønior partner, O. W. Roskill, Industrial Consultants), "The Investigation of Trends of Consumer Tastes", by Mr. L. R. England (chief research officer, "Mass Observation"), and "Market Research and the Seller", by Mr. D. S. F. Vernon (Calico Printers' Association, Ltd.).

Mr. Vernon directed attention to influences such as machine production and increased mobility which were at work in the nineteenth century and which had the result of separating the producer from the consumer: "It is to bridge the gap between producer and consumer and appreciate more clearly 'consumer preference' (consumer requirements) that a scientific study of these factors has come to the fore under the label of Market Research". The other speakers noted the remarkable lack of knowledge of their own markets which was displayed by many manufacturers, even the efficient ones; and interesting examples were given by Mr. England and the other speakers of astonishing misconceptions as to the strength (or weakness) of customers' preference for a particular product.

In describing the technique of market surveys, Mr. Roskill observed four main avenues of investigation calculated to facilitate the establishment of the manufacturer's sales plan : the division of consumption into the separate uses for the goods in question, a survey of the factors affecting demand, an analysis of the channels of distribution and a knowledge of competition.

As might well be expected from a conference taking place in Lancashire, the treatment of the subject of market research was by no means confined to its relationship with consumable goods. In particular Mr. Vernon was concerned with the importance of investigations of textile markets, where the product is not one which is packed at the factory ready for final consumption, but a fabric which may be used for a variety of purposes. Similarly, Mr. Roskill devoted considerable attention to the technique of market research in relation to producer goods, and it is refreshing to note his emphasis upon the marketing problems which confront those manufacturers who are not concerned with the final retail consumer, but as sellers of semi-finished material, machine tools and other forms of industrial equipment are involved as links in a long chain of manufacture. In consequence, any analysis of the factors affecting the demand for their products cannot be limited to one immediate customer, but may involve an investigation extending into industries one, two, or even three times removed from the industry immediately under survey.

An aspect of market research which might perhaps have been elaborated with profit is the extent to which the manufacturer, having been presented with an analysis of his market, could venture to mould the demand to correspond with his manufacturing conditions. In so far as the market survey discloses the reasons for the preferences of customers, it should be possible to make some estimate of the risks involved in persuading them to accept articles which do not entirely conform to their tastes and prejudices, but which present advantages from the manufacturing point of view. The problem is one which is exercising the minds of manufacturers to-day, particularly those concerned with export markets, and invaluable guidance would be given to them if it were possible to assess the probable reactions of foreign customers, for example, to a policy of greater standardization directed towards the reduction of manufacturing costs by increasing the length of runs on relatively few models.

\section{PROBLEMS OF SOIL AND LAND CLASSIFICATION}

$\mathrm{T}$ HE newly formed British Society of Soil Science held its first conference during September 26-29 in Oxford; the principal topic of discussion centred on problems of soil and land classification.

The first session was devoted to the problems of soil classification, which fall into two categories: how far can soils, which show continuous gradations from one type to another, be divided into types with sufficiently sharply defined differences, so that a soil map can be made of a whole region; and whether the soil map should be made without any reference to the use to which it will be put. Mr. C. G. T. Morison (Oxford), Prof. G. W. Robinson (Bangor) and Prof. S. W. Wooldridge (London) read papers at this session and many members took part in the discussion.

The first two speakers were concerned with mapping soils by 'associations'. In any one region the soil will vary because, as Prof. Robinson put it, the soil is a passive agent of variable constitution acted upon by climate, vegetation and so forth, and these vary over the region. In many regions most of these active agents remain fairly constant with only one or two changing appreciably. Such an area can then 


\section{No. 4072 November 15, $1947 \quad$ N A T U R E}

be mapped, not by mapping the individual patches of the different kinds of soils present, patch by patch, but by indicating that all variations occur in regular succession between certain types. This includes both the ordinary method of mapping associations and Milne's method of recognizing catenas. The principle is easily applied if only one soil-forming factor is varying appreciably over the region, but becomes more difficult to apply if several are varying. Prof. Wooldridge discussed the more specific problem of the value of recognizing the geomorphological age of the surface on which the soil is formed, and illustrated the points he made by discussing the chalk surfaces of southern England.

The second session was devoted to problems of land classification. Here the problems are of immediate interest to the community, since they concern the conflicting demands upon the use of land for buildings, mineral exploitation and food production. Dr. E. C. Willatts described some of the problems confronting the administrator who has to approve certain types of land use, developments and changes to ensure they are consistent with the policy laid down in the White Paper on "The Control of Land Use" (Cmd. 6537) and in subsequent legislation. By clearly stating the problems facing land planners, he hoped that soil surveyors and other people who had to assess the value of land would prepare their results in such a form that the administrator could easily understand and use them.

Dr. D. A. Osmond gave the definitions, adopted by the West Midland Group on Post-War Reconstruction and Planning, for classifying agricultural land into three categories of good, medium and poor on the basis of its inherent features of site and soil. Site involves the consideration of aspect, slope and elevation, while water-conditions, depth and texture are taken into account as soil factors. Using this simple classification, the major categories of agricultural land can be readily picked out. Eight western counties of England have been mapped on this basis. Because of the high farming on soils frequently of medium quality, market garden areas such as the Vale of Evesham, and some other districts, are included in sub-categories of good agricultural land.

Mr. F. R. Day (Oxford) then discussed criteria for judging the economic value of land for forestry. $\mathrm{He}$ showed that if the tree is to come to a proper height at maturity, or at a given age, there is an optimum curve relating its rate of growth with age for each species of tree in a region. Any falling off from this curve is due to some soil factor making the site less suited for the economic exploitation of that species. $\mathrm{He}$ illustrated these points by discussing the rate of growth of forest on thin or wet land, often considered suitable for forestry because unsuitable for agriculture, and showed that growth of many species is too slow for economic exploitation, even though initially the growth may be very rapid.

Finally, Mr. G. R. Clarke (Oxford) described the gravel survey of the London area, a survey undertaken to map the good, medium and indifferent agricultural soils overlying the gravel. The object was to see how far it would be possible to prevent the exploitation of the gravels under the best agricultural and market garden land and to continue their exploitation under the poorer soils. Unfortunately, as Prof. Wooldridge later pointed out, there are many different types of gravels, and some essential for making concrete only occur in sufficient quantity under some of the best agricultural land.

\section{TUBERCULOSIS OF VOLES AND SHREWS}

TT is ten years since Dr. A. Q. Wells reported the presence in the wild vole (Microtus agrestis) of a murine type of tubercle bacillus; since then a good deal of work has been done upon this organism. Tuberculosis has been found also in the bank vole (Clethrionomys glareolus), the wood mouse (Apodemus sylvaticus) and the shrew (Sorex araneus), and the relationships of this murine type of tubercle bacillus to the bacilli which cause human and avian tuberculosis have been carefully studied. The present position of our knowledge of the problems raised by the discovery of this bacillus has now been ably stated by Dr. A. Q. Wells in a report entitled "The Murine Type of Tubercle Bacillus (The Vole AcidFast Bacillus)", to which Dr. A. H. T. Robb-Smith has contributed notes on the morphology of infection by the vole acid-fast bacillus.*

Illustrated by very clear photographs and by graphs and diagrams, this report is a valuable addition to the literature about tuberculosis. The structure, cultivation, antigenic structure, pathogenicity and other features of the vole bacillus are all discussed, and Wells concludes that the statement that the disease which it produces is tuberculosis "seems justified, in spite of the fact that tuberculosis as a disease of other wild animals in their natural habitat has not hitherto been found". It is not possible to separate the vole bacillus from the human or bovine bacilli tubercle by serological methods; animals infected with the vole bacillus are sensitive to human or bovine tuberculin, and animals infected with human or bovine tubercle bacilli are sensitive to a tuberculin prepared from the vole bacillus. The vole bacillus can, moreover, produce progressive disease of the animals which it can infect, and this disease is indistinguishable from that produced by human or bovine tubercle bacilli. The vole bacillus is therefore a third type of tubercle bacillus. One of the most valuable sections of this report discusses experiments which have been designed to find out whether experimental infection of laboratory animals with the vole bacillus will confer any degree of immunity to the human or bovine tubercle bacilli. The use of a vaccine prepared from the vole bacillus for the production of immunity in man is also described; and the instrument used for some of these experiments, which enables forty simultaneous punctures of the skin to be made, is described and illustrated. Wells discusses the results obtained and also the relative merits of B.C.G. vaccine and the vole bacillus vaccine. An evaluation of the results obtained can be made only by experts who have a wide experience of that kind of work. Those who are interested must read the report itself.

Dr. A. H. T. Robb-Smith's notes on the lesions produced by the vole bacillus and the excellent photographs of them with which he illustrates his notes are a worthy addition to the report. Everyone who is interested in the intricate problems presented by tuberculosis will be grateful for the inclusion in a single compact and well-written publication of so much information, together with the references to the literature which are relevant to it.

\section{G. LAPAgE}

* Medical Research Council. Special Report Series, No. 259. The Murine Type of Tubercle Bacillus (The Vole Acid-Fast Bacillus) with Notes on the Morphology of Infection by the Vole Acid-Fast Bacillus. By A. H. T. Robb-Smith. Pp. iv $+48+13$ plates. (Iondon: H.M. By A. H. T. Robb-Smith. Pp. iv
Stationery Office, 1946.) 28. net. 